\title{
The Effect of (E-glass) Fibers and Glass Powder Addition on the Alternating Fatigue Behavior of Unsaturated Polyester Resin
}

\author{
Moyed A. Al-Nueimi $\quad$ Edrees E. Al-Obeidi \\ Department of Physics \\ College of Science \\ University of Mosul
}

E-Mail: adreesedaan@yahoo.com

(Received 9/10/2012; Accepted 18/3/2013)

\begin{abstract}
In this research, our concentration was directed to study the effect of weight fraction of the reinforcement materials (E-Glass) chopped strand laminates fibers, (E-Glass) continuous fibers and Glass powder, on the alternating bending fatigue behavior of the unsaturated polyester matrix (polymeric composite).

The result of this study reveals that the variation of the weight fraction percentage of the reinforcement materials could affect the fatigue resistance of the produced composite.

It has been noticed that the increase in the weight percentage fraction of both, glass laminates fibers (No. of laminates) and the glass continuous fibers, contributed effectively to improve the fatigue resistance, this reflects the longer fatigue life of the composites, that increase in the fatigue life could approach to more than hundred times, in the case of using glass laminate fibers and to more than twenty four times, in the case of using glass continuous fibers, at the same stress levels $(9 \mathrm{MPa})$, and the same percentage of weight fraction $(6 \mathrm{wt} \%)$.

The result obtained of fatigue test in the case of using glass powder, suggests that the fatigue life depends on the percentage of weight fraction. The results also reveal an improvement in fatigue life three times longer for the weight fraction $(2.5 \mathrm{wt} \%)$, of glass powder, but the higher weight fraction $(6 \mathrm{wt} \%)$, reduced the fatigue life to a third compared to unreinforced base matrix.
\end{abstract}

Keywords: Composite materials, polyester, glass fiber, glass powder, bending fatigue (alternating), fatigue behavior.

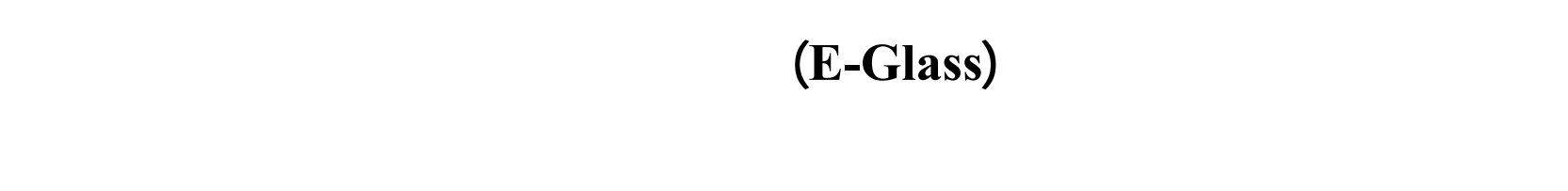

\section{الملخص}

في هذا البحث م الزركيز على درلسة تأثير نسب مواد القوي ـة (ألي لف الزج الج i -وع (E-Glass)

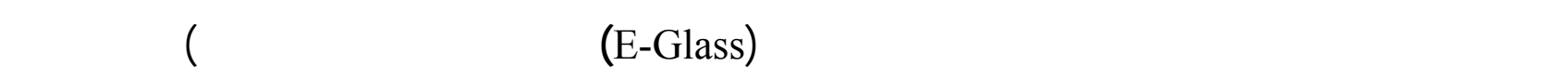
الكلا الانحنائي ألتناوبي لمادة الأسلس البوليمرية نوع بولي لأستر غير المجاف المشع. 
لظاهرت نتائج الدرلسة أن التغير في النب الوزنية المئوية المضلفة يؤثر على مقاومة الكلل ألتناوبي،

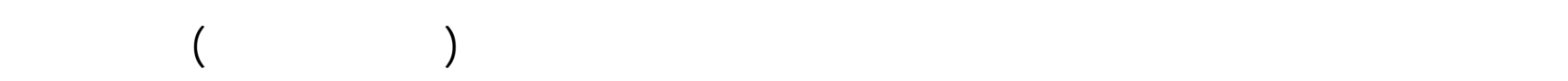

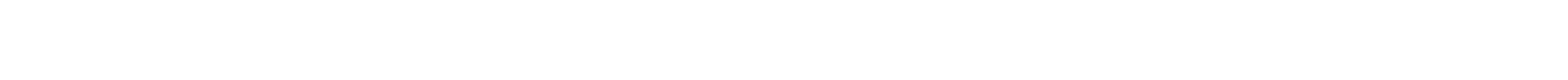

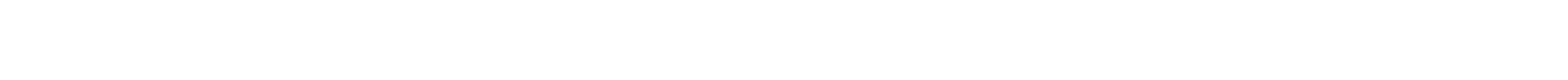

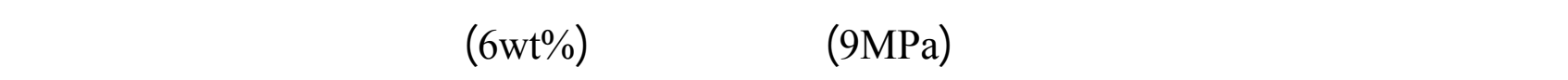

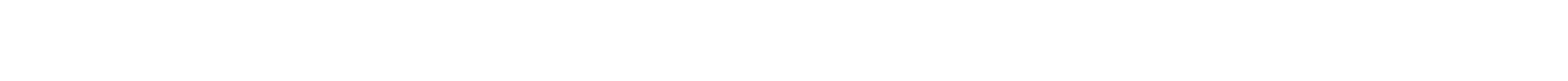

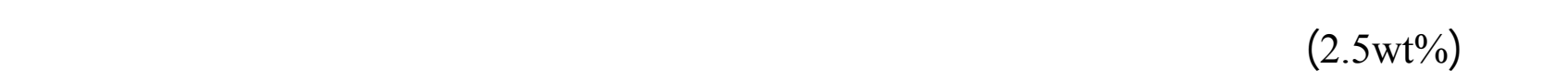
رفع النبة الوزنية إلى (6wt\%) يؤدي إلى تناقص عمر الكلال بمقدار الثلث.

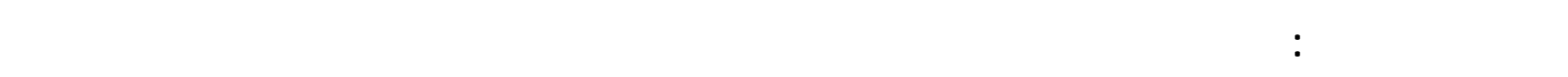 الانحنائي(ألتناوبي)،سلوك الكلل.}

\section{INTRODUCTION}

Over the past few decades, composite materials have replaced many of the conventional metals / materials in various applications. This is possible because of the advantage of composite materials offer over conventional materials (Karina et al., 2008).

The most important advantages of using polymers are low density, high strength, high rigidity, ease of processing, productivity and low cost reduction (Sakin et al., 2006). The light weights of these composites also increase the energy efficiency for machine and transportation (Mohammed et al., 2009).

One of the most common and familiar composites is fiber and powder glass, in which glass fibers or powder are embedded within a polymeric material (William, 2000).

Fiber glass reinforced polymer matrix composites are finding ever-increasing usage for numerous industrial applications, such as bearings material, rollers, seals, gears, cams, wheels, clutches, etc. There is a large use of glass fibers in this field because of its strong and stiff properties (but also brittle), whereas the polymer is ductile (but also weak and flexible). The combination of a plastic matrix and the reinforcing glass fibers gives rise to composites having the best properties of each component (El-tyeb et al., 2005).

Glass powder are most often added to polymers to improve tensile and compressive strength, abrasion resistance, toughness, dimensional and thermal stability of, and other properties. Because these inexpensive materials replace some volumes of the most expensive polymer, the cost of the final product is reduced (William, 2000).

Glass fiber reinforcement polymer (GFRP) materials are preferably used in wind turbine blades, in air, sea and land transportation. Most of these materials are subjected to a cycle loading during the service condition that mostly causes fatigue damages (Tomita et al., 2001) (Kim et al., 1999) in a picture of cracks starting and growing and eventually, the fan blade is broken (Rowler, 1996).

The mechanisms of composite materials under cycling loading and their fracture behaviors are really complex, for this reason, the study which has been done to identify the 
fatigue behavior under the cycling loading is essential for using composite materials safely (Khashaba, 2003).

Moreover, The fan blades which are made from composites are subjected to the gravitational force, a centrifugal force and a wind force. A wind force has a relatively low frequency and high amplitude and it is the most dominant force on the fatigue damage. This also generates alternating bending stresses (tension-compression) (Irfan et al., 2008).

Fatigue damage results in a change of strength, stiffness and other mechanical properties of composite material. Damage phenomena under various loading conditions are significantly different for polymeric composites. Damages can occur by: crack formation due to fiber breakage, matrix crack propagation, fiber-matrix debonds, void growth and delamination. Anyone or a combination of these mechanisms may lead to a reduction of the strength.

In many fatigue studies, the fatigue performance of materials is analyzed by investigating the relationship between the fatigue load (S), either applied stresses, and the fatigue life (number of cycles to failure (N)) (Botelho et al., 2009). Therefore the use of these materials can be decided in a better way by knowing their fatigue behaviors. For this aim, generally (S-N) diagrams are used (Caprino and Giorleo, 1999).

In a review of some of the literature concerning fatigue behavior of composite under cyclic loading. (Mallicks, 1981) experimentally investigates the Static and dynamic fatigue properties of the composites of different matrix (vinyl ester and polyester) and filler (glass content sheet or calcium carbonate powder) types, the result shows that matrix plays an important role in both fatigue characteristics and failure mechanisms of such randomly oriented short glass fibers composites or calcium carbonate powder. Specifically, vinyl ester matrix with glass fibers show better fatigue properties and post-fatigue performance than vinyl ester matrix with calcium carbonate powder and the polyester with glass fibers or calcium carbonate powder system.

(Berkowitz and Johnson, 2005) study the effect of temperature on the fatigue behavior of graphite/epoxy composite. They found that the fracture toughness of this composite increased with the corresponding reduction in temperature and the cold temperatures resulted in slower fatigue crack growth rates than at room temperature, while hot temperatures caused faster fatigue crack growth rate in the core.

(Ferreira et al., 2005) reported in details the effects of fiber contents and the resin in the fatigue strength of epoxy and polyester resins reinforced by aluminized glass fibers, then they compared this results with those obtained from conventional glass fiber composites. The failure mechanisms were analyzed using microscopy, they show that the tensile and fatigue strength of aluminized composite is lower than unaluminized composites. This is associated with the fabrication defects and aluminum interface with fibers and resins when compared to uncoated glass fibers.

(Shahzad and Isaac, 2009) reported that the impact, tensile and fatigue behavior of polyester resin matrix composite are reinforced by hemp fibers. The result shows that the increasing of fibers content improves the impact, tensile and fatigue performance of this composite, then they also noted that there was a little effect of water immersion on impact and tensile damage. Additionally, minimal stiffness degradation and damage accumulation during fatigue provided no warning of the final brittle failure. 
This work focuses on the preparation kinds of polymeric composite materials prepared from the unsaturated polyester resin as matrix reinforced by:

1. (E- glass) chopped strand laminates.

2. (E- glass) continuous fibers.

3. Glass powder.

The aim of this study is to investigate:

- the effect of the selected weight fractions $(1.25 \%, 2.5 \%, 3.7 \%, 4.9 \%, 6 \%)$ of the (E-glass) fibers and powder on the fatigue behavior of the prepared composite materials, which are done at room temperature.

- the failure mechanism of the composite materials under-cyclic loading and their fracture behavior.

\section{Materials}

\section{THE EXPERIMENT}

The matrix used in this study was unsaturated polyester resin manufactured by the accompany of (SIR Saudi Arabia). It is viscous liquid, transparent, pink, good mechanical properties, bonding with other materials, thermal and electrical insulation, good surface after setting, dimension stability and it is type of thermosetting polymer, Table (1) gives some properties of unsaturated polyester resin (Chungm, 2010):

Table 1: Mechanical properties of unsaturated polyester resin (Chungm, 2010)

\begin{tabular}{|c|c|c|c|c|c|c|c|}
\hline Name & $\begin{array}{c}\text { Density } \\
\left(\mathrm{gm} / \mathrm{cm}^{3}\right)\end{array}$ & $\begin{array}{c}\text { Fracture } \\
\text { toughness } \\
\left(\text { MPa.m }^{0.5}\right)\end{array}$ & $\begin{array}{c}\text { Tensile } \\
\text { Strength } \\
\text { (MPa) }\end{array}$ & $\begin{array}{c}\text { Percent } \\
\text { Elongation } \\
(\text { EL\%) }\end{array}$ & $\begin{array}{l}\text { Modulus of } \\
\text { Elasticity } \\
\text { (GPa) }\end{array}$ & $\begin{array}{c}\text { Compression } \\
\text { Strength } \\
\text { (MPa) }\end{array}$ & $\begin{array}{c}\text { Bending } \\
\text { Strength } \\
\text { (MPa) }\end{array}$ \\
\hline $\begin{array}{l}\text { Polyester } \\
\text { resin }\end{array}$ & 1.2 & 0.6 & $89.7-41.4$ & $<2.6$ & $2.06-4.11$ & 100 & 125 \\
\hline
\end{tabular}

The liquid resin is converted to solid by mixing (2\%) of methyl ethyl ketone peroxides (MEKP) as a hardener with $(0.4 \%)$ Cobalt actuate as an accelerator to solidification. This mixing is done for each $(100 \%)$ of unsaturated polyester resin at room temperature.

\section{Fiber Glass}

In this research, the reinforcement materials type (E-Glass) used as laminates chopped strand mat was about $(4 \mu \mathrm{m})$ in diameter and continuous fibers about $(60 \mathrm{~mm})$ in length and $(6 \mu \mathrm{m})$ in diameter have been used for strengthening the matrix (Unsaturated polyester). Table (2) gives the composition of the (E- glass) fibers (Wake, 1977):

Table 2:Composition of ( $\mathrm{E}$ - glass) fibers

\begin{tabular}{|c|c|c|c|c|c|}
\hline $\mathrm{SiO}_{2}$ & $\mathrm{Al}_{2} \mathrm{O}_{3}$ & $\mathrm{CaO}$ & $\mathrm{MgO}$ & $\mathrm{Na}_{2} \mathrm{O} / \mathrm{K}_{2} \mathrm{O}$ & $\mathrm{Ba}_{2} \mathrm{O}_{3}$ \\
\hline 52.4 & 14.4 & 17.2 & 4.6 & 0.8 & 10.6 \\
\hline
\end{tabular}


These fibers (laminates or continuous) were immersed in the form of regular manner into the resin.

\section{Glass powder}

Glass powder is generally the inert materials which are used in composite materials to reduce material costs, improve mechanical properties to some extent, toughness, high heat resistance, high sound and electric insulation, great chemical resistance and in some cases to improve process ability.

Glass powder of particle size $(2-4 \mu \mathrm{m})$ added in the final of mixing a resin, gradually and slowly with the hardener and accelerator in a beaker at room temperature.

\section{Composites Preparation}

1- The specimens made of (E-glass) laminates fiber reinforced polyester (GLRP), (E-glass) continuous fiber reinforced polyester (GCRP) and glass powder reinforced polyester (GPRP) composite were prepared by using hand-lay-up and open mould techniques.

2- The glass mould was cut and cleaned, with dimensions $(10 \times 60 \times 3) \mathrm{cm}$ for the fatigue tests.

3- The mould has initially been polished with release agent to prevent the composites from sticking on the mould upon removal.

4- The weight percent of the fiber or powder in the composite was ranging $(1.25-6)$, and calculated by Eq. (1) :

$\mathrm{Wt} \%$ of the fibers in the composite $=\frac{\text { Weight of fibers }}{\text { Weight of polyester }+ \text { weight of fibers }} \times 100 \%$

5- The (GLRP) (1-5 ply) or (GCRP) with weight fraction as mentioned before were impregnated with resin by pouring the resin from one corner to the mould to the fixed level, then the fibers put into the mould, then the other resin was uniform pouring to the mould. The pouring continued until the mould was filled to the required level, to avoid the bubble formation which causes cast damage.

6- The reinforcement filler of (GP) and the matrix (including the accelerator and the hardener) were mixed at room temperature continuously and slowly to avoid bubbling during mixing. The process continued for (5) minutes until the mixture became homogeneous. Temperature rose which indicated the beginning of reaction process. Temperature raising was very necessary for the mixture to have a certain viscosity and to avoid particle precipitation, then the mixture was poured from one corner into the mould to avoid the bubble formation which causes cast damage and the uniform pouring continued until the mould was filled to the required level.

7- All samples was then pressed in a $\left(3.33 * 10^{5} \mathrm{~N} / \mathrm{m}^{2}\right)$ and was left in the mould for (24) hrs at room temperature to solidify, then, taken out of the mould and kept in the air for another (24) hrs.

\section{Mechanical tests \\ Fatigue test}

The bending fatigue testing machine type (HSM20) was used as shown in Fig. (1) made by (Hi - Tech) British company, which exists in the Dpt. of Physics / University of Mosul / College of Science. 


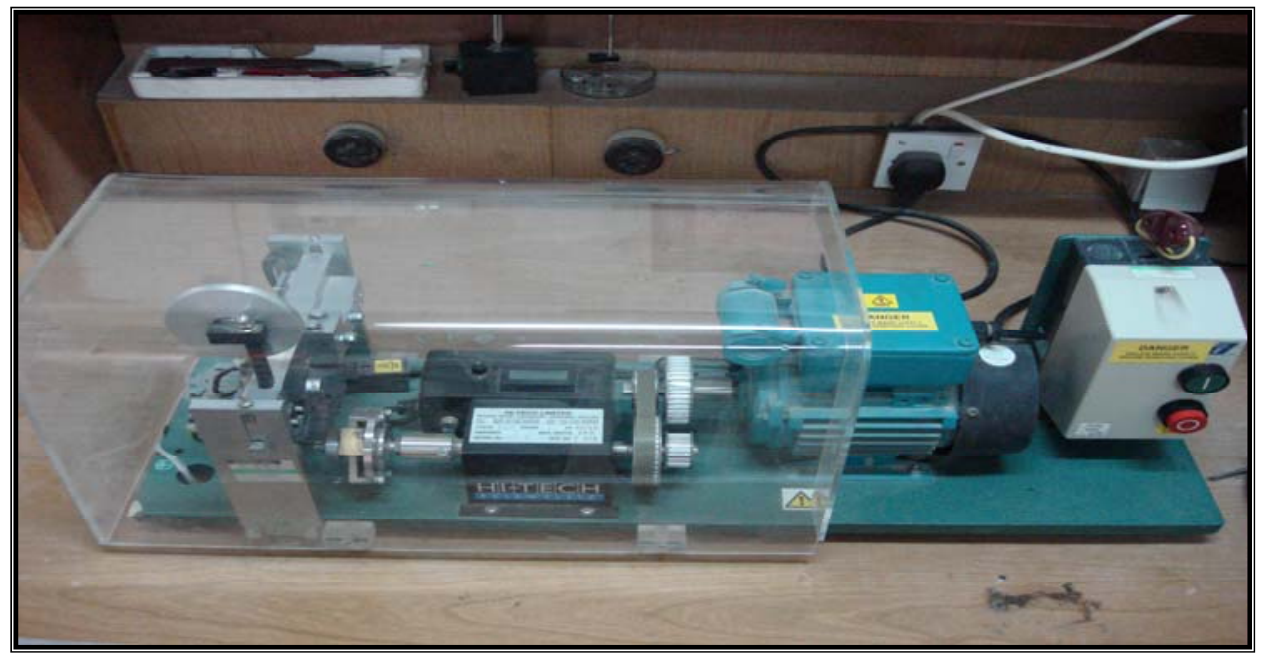

Fig. 1: Bending fatigue machine

The samples used, were prepared according to the manual, as shown in Fig. (2).

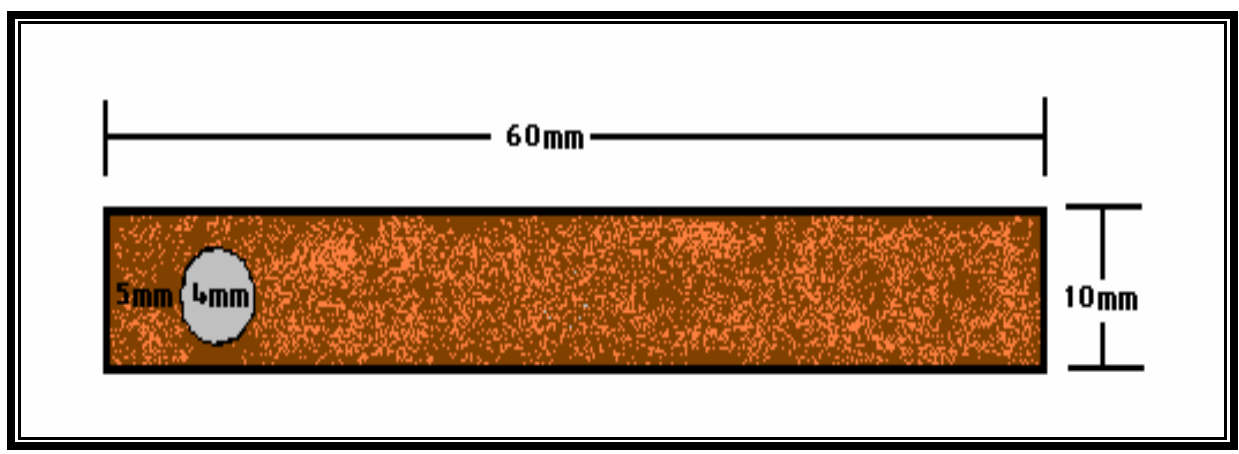

Fig. 2: Sample of fatigue test

In this study, the practical test frequency was kept constant, at room temperature of about $\left(20^{\circ} \mathrm{C}\right)$.

By neglecting the gravitational and centrifugal forces, the maximum load was calculated by Eq. (2) (William, 2000) :

$$
\sigma_{\max }=-\sigma_{\min }=\frac{6 P L}{B T^{2}}=3 P
$$

Where :

$\sigma_{\max , \min }$ : The maximum and minimum stress value, respectively $(\mathrm{MPa})$.

$\mathrm{P}:$ Applied load $(\mathrm{N})$.

L : Distance from the applied load position to the fractured area $(\mathrm{mm})$.

B : Sample width (mm).

$\mathrm{T}$ : Sample thickness (mm). 
The machine was designed to apply constant amplitude reverse loads with $(\mathrm{R}=-1)$, where, $(\mathrm{R})$ is the ratio of the minimum stress to maximum stress applied to the samples.

$$
R=\frac{\sigma_{\text {min }}}{\sigma_{\text {max }}}
$$

The bending stresses are equal to each other, i.e. $\left(\sigma_{\max }=-\sigma_{\min }\right)$. The fatigue tests were carried out until the specimen fracture and the $(\mathrm{S}-\mathrm{N})$ curves were plotted from the test results of all composites.

\section{RESULT AND DISCUSSION}

In order to study the effect of reinforcements on improved fatigue behavior and to gain a better understanding of the underlying crack propagation mechanism in the polymer matrix, optical microscopic pictures of fractured region were considered for analysis.

In optical microscope analysis, it has been found that the standard sample or the unreinforced polyester sample was transparent and pure as shown in Fig. (3).
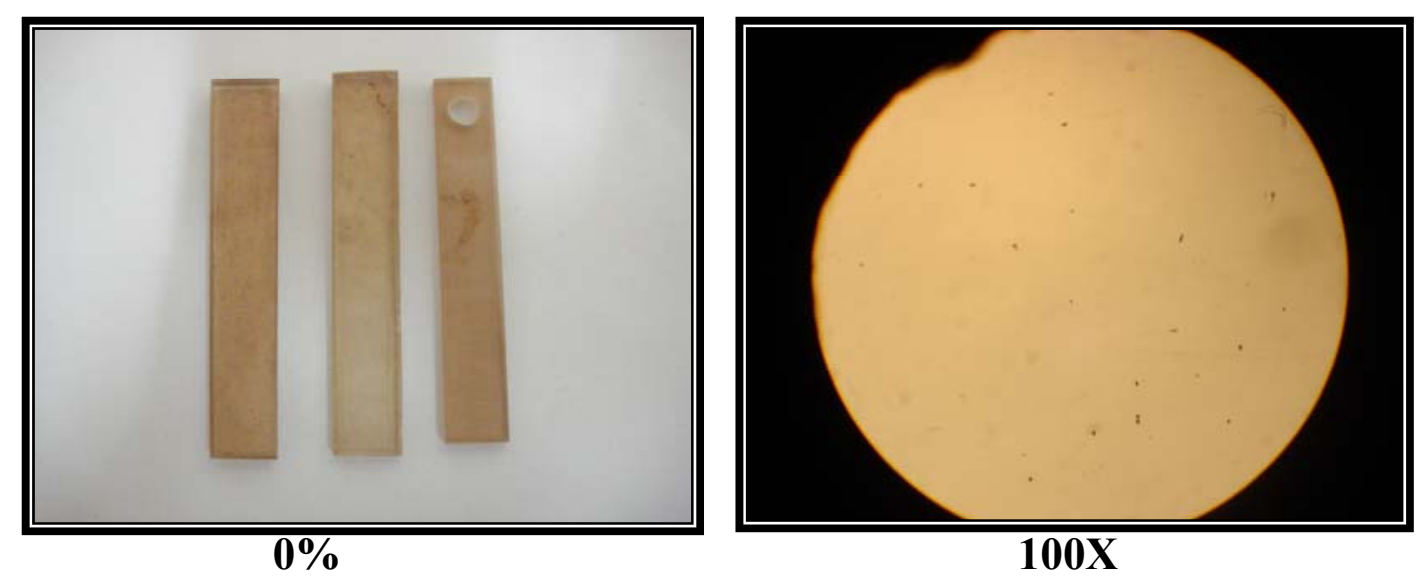

Fig. 3: Microstructure of the standard sample

Fig. (4) shows the random distribution of glass particles, which reveals the increases in the concentration of glass particles, when the weight percentage increased. Air bubbles or voids can also be increased by with increasing the weight fraction of glass powder, this voids could be initiated from :

- Induced during different prepared process conditions.

- Chemical compositions of glass powder that contains element have oxygen atom such as $\left(\mathrm{SiO}_{2}, \mathrm{Al}_{2} \mathrm{O}_{3}, \mathrm{CaO}, \ldots\right)$. 


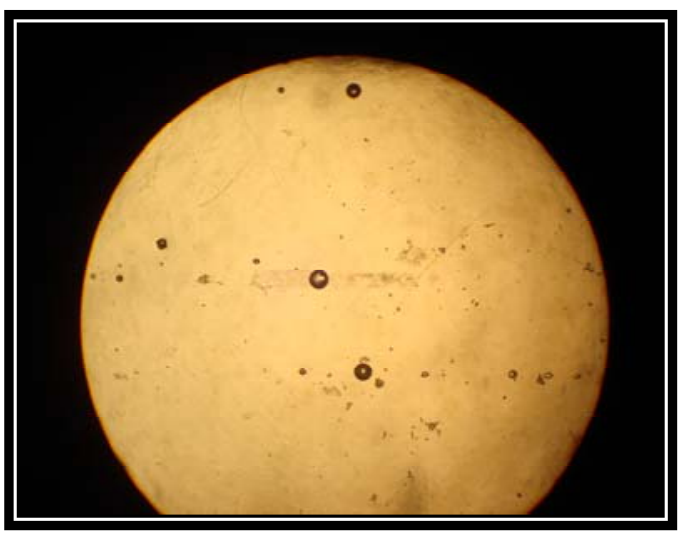

$1.25 \%, 40 X$

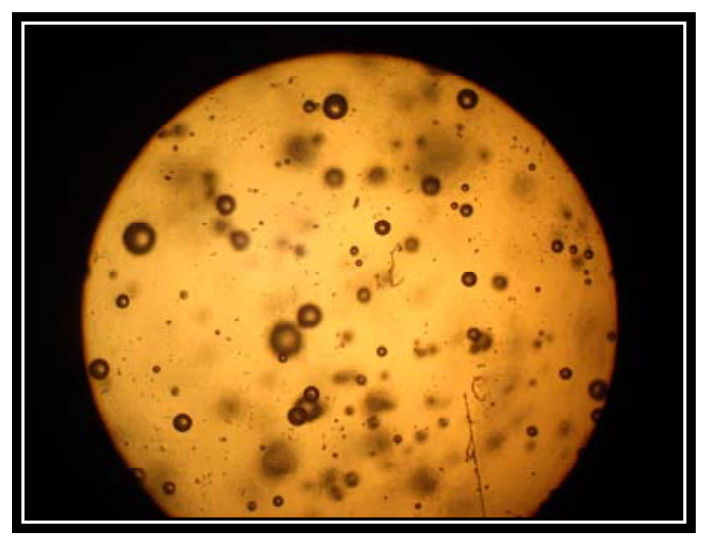

$4.9 \%, 40 X$

Fig. 4: Microstructure of different weight fraction of glass powder composite

In the case of glass laminates fibers Fig. (5) and glass continuous fibers, Fig. (6) few creation of air bubble or voids.

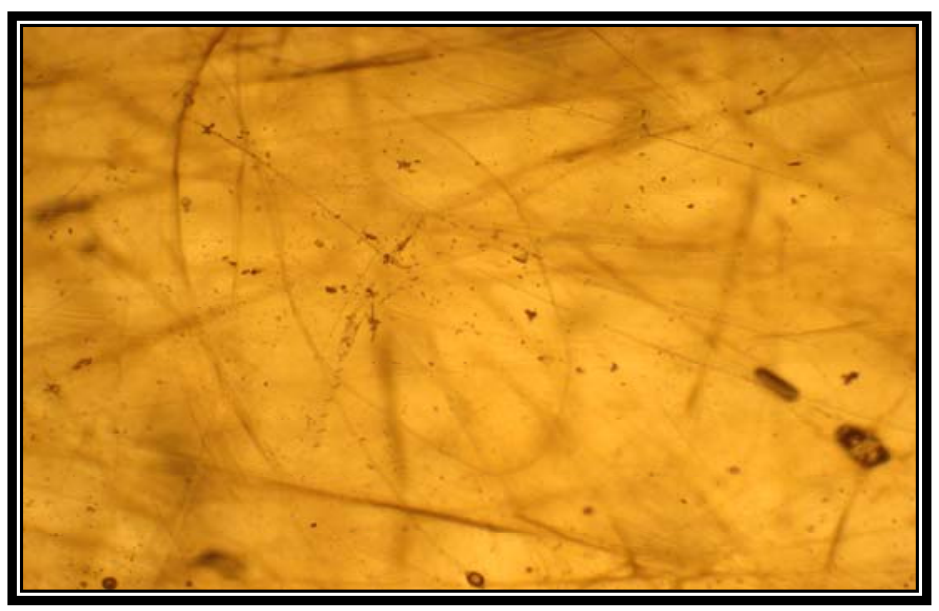

$6 \%, 120 X$

Fig. 5: Microstructure of glass laminates fibers composite

Because of the fast solidification of the resin, the addition of glass continuous fibers led to a little random distribution of these fibers in the resin during the prepared process.

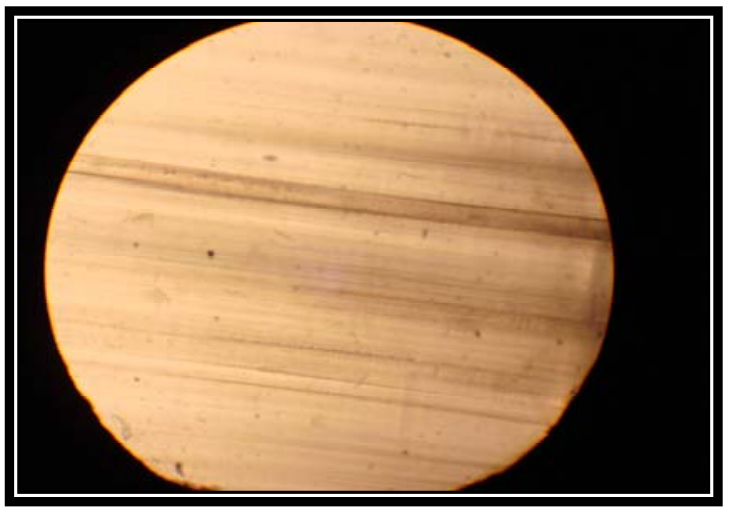

$1.25 \%, 400 X$

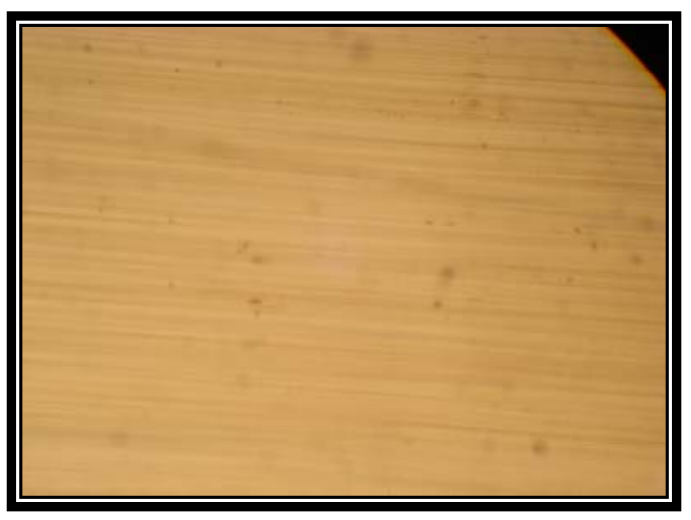

$2.5 \%, 170 X$

Fig. 6: Glass continuous fibers composite microstructure 
However, the increasing of the weight fraction of glass fibers laminates, continuous and powder led to an increase in the nontransperency (fogy) of prepared composites.

\section{Fatigue test}

The fatigue properties of glass powder, laminates and continuous fibers varied considerably, depending on the chemical and structural composition, fiber type, growth conditions, the adhesion between the matrix and fibers and the direction of the fibers.

To identify the fatigue life of all specimens prepared, $(\mathrm{S}-\mathrm{N})$ diagrams were obtained from experimental data. The composite (S-N) plot gave a better idea of the material behavior in response to fatigue loading.

\section{Fatigue behavior of unsaturated polyester}

The fatigue behavior of standard samples is shown in Fig.(7); the specimen failed quickly, because of the entire crack formation and growth sequence occurred at fast manner during fatigue test.

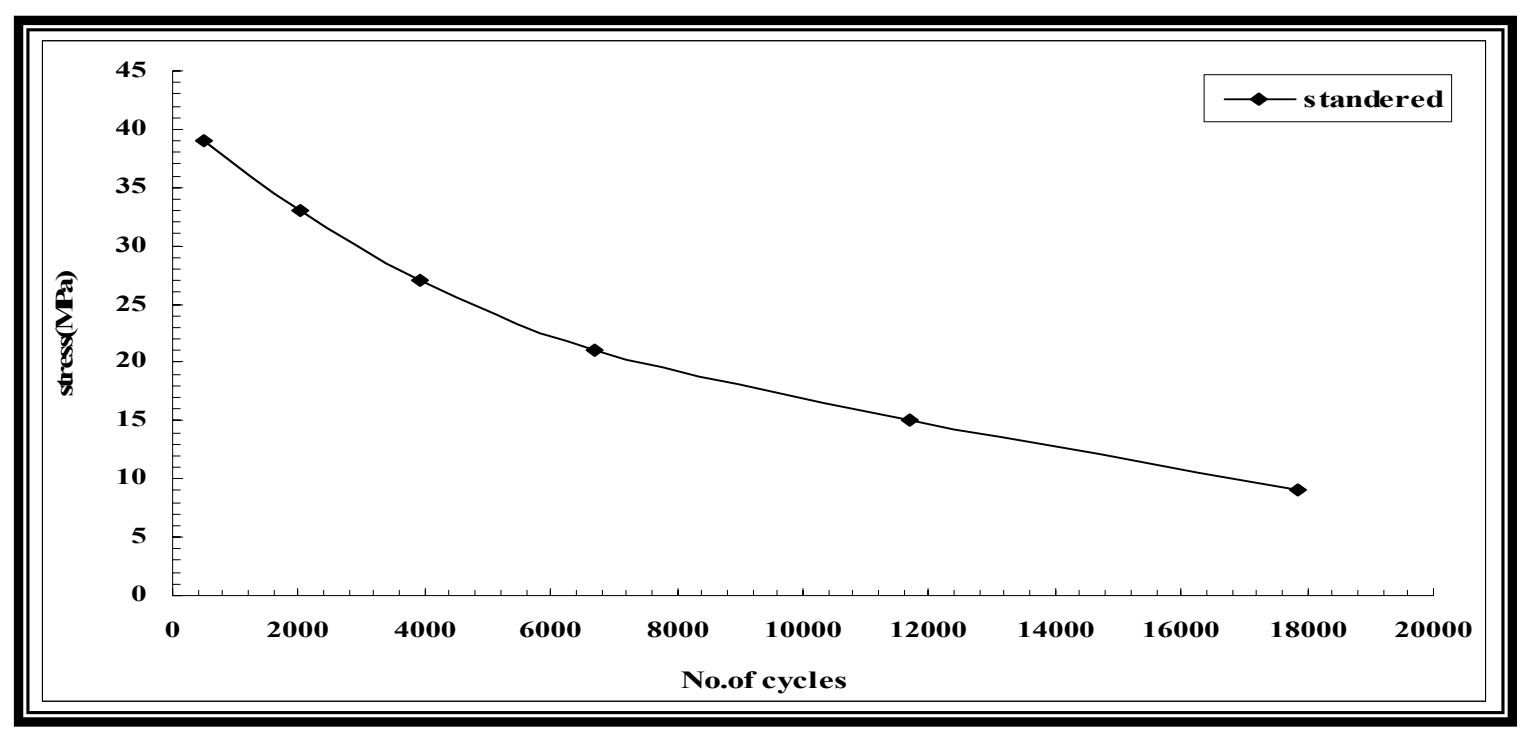

Fig.7: Fatigue life of unsaturated polyester

The brittle nature of the fractured region of a typical sample cracked in fatigue testing is shown in Fig. (8).

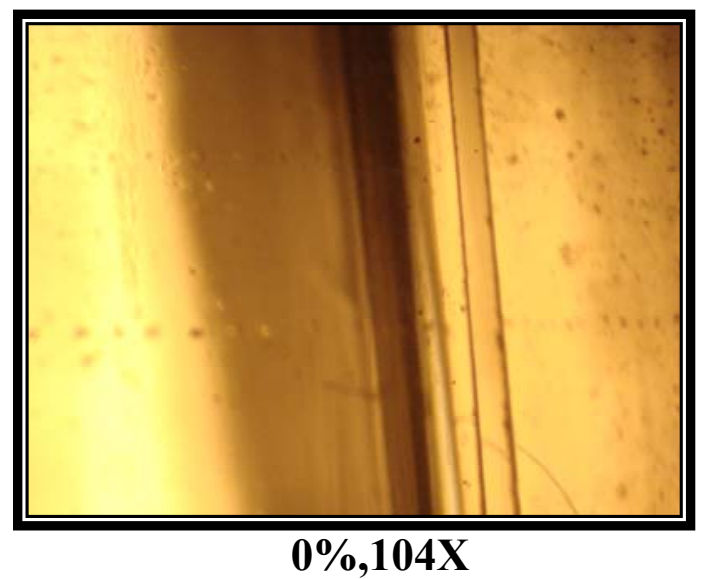

Fig. 8: Fractured surface of standard sample 
The samples failed in a completely brittle with a sharp edge and catastrophic manner, normal to the direction of applied stress, and cover the whole width of the specimen and no crack or plastic deformation was seen to form on the surface before the eventual failure.

The typical cross-section of the fractured region after cyclic fatigue test is presented in Fig. (9); which indicates points of crack initiation followed by striations and beach marks that map instantaneous positions of crack tip during the fatigue crack propagation.

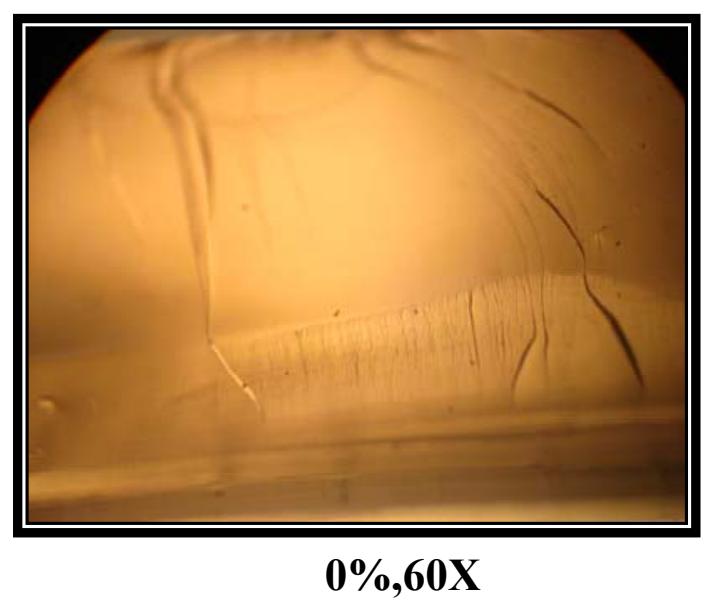

Fig. 9: Fractured cross-section of standard sample

\section{Fatigue behavior of glass laminates fiber composite}

All specimens that have been used in this part of the work were failed with the applied load levels, as shown in Fig. (10).

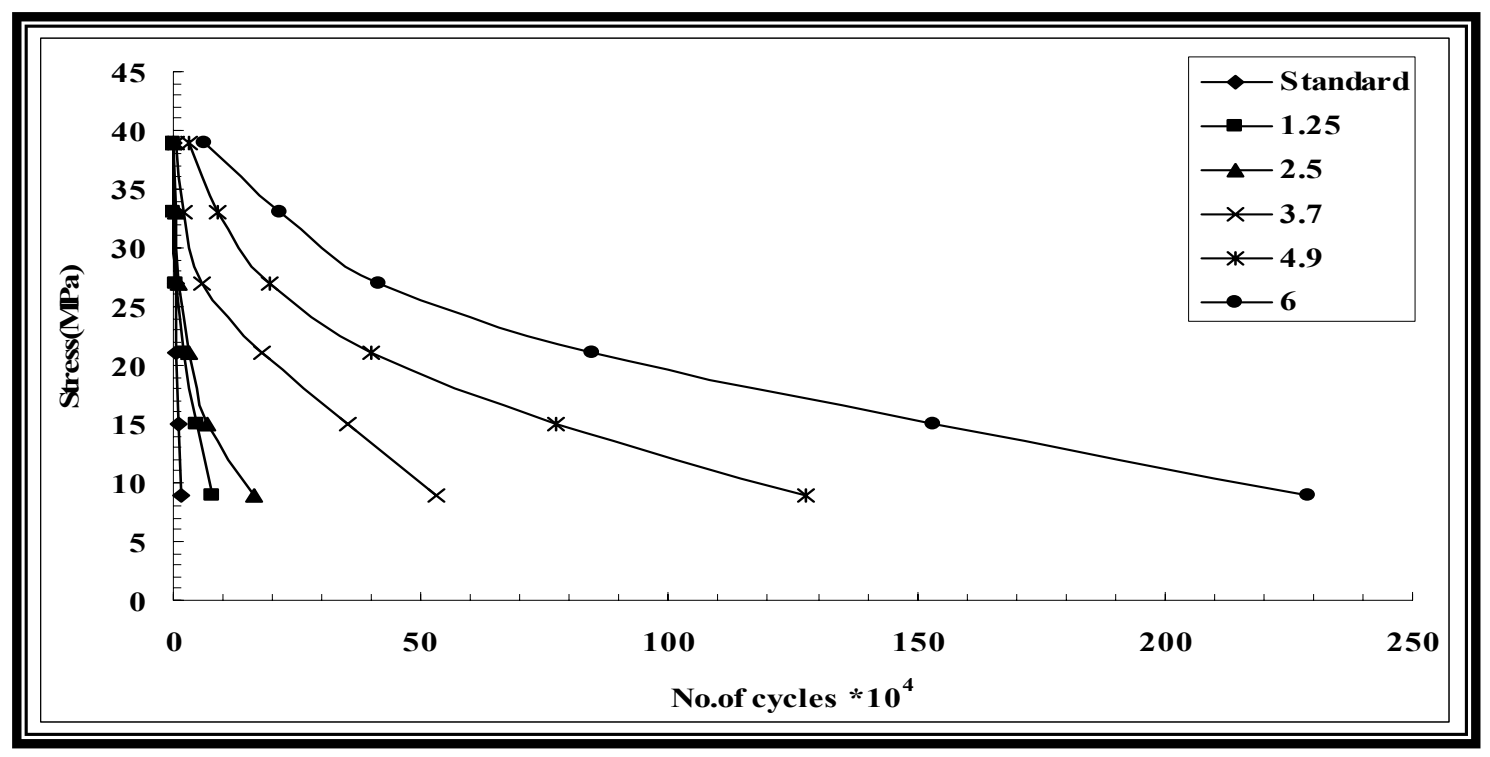

Fig. 10: Fatigue life of glass laminates fibers composite 
It is clear that the fatigue life of these composites have show a considerable improvement with an increase in the weight fraction of the reinforcement material. This improvement approach (4.5) times than the standard sample at fatigue stress (9MPa) and concentration and (1.25\%) weight percent of glass fibers because fibers bear most of the applied load, as shown in Table (3). This improvement is observed in all samples, which means that these composites showed a better resistance against fatigue failure.

Table 3: Fatigue life $V_{S}$ the weight fraction of glass laminates fibers composite

\begin{tabular}{|c|c|c|c|}
\hline $\begin{array}{c}\text { Weight fraction } \\
(\mathbf{w t} \%)\end{array}$ & $\begin{array}{c}\text { Fatigue strength } \\
\text { (MPa) }\end{array}$ & $\begin{array}{c}\text { Fatigue life } \\
\text { (No.of cycle) }\end{array}$ & Times of improvement \\
\hline 0 & 9 & 17844 & $0 \mathrm{X}$ \\
\hline 1.25 & 9 & 80612 & $4.5 \mathrm{X}$ \\
\hline 2.5 & 9 & 160422 & $9 \mathrm{X}$ \\
\hline 3.7 & 9 & 532189 & $30 \mathrm{X}$ \\
\hline 4.9 & 9 & 1275674 & $71.5 \mathrm{X}$ \\
\hline 6 & 9 & 2291238 & $128.5 \mathrm{X}$ \\
\hline
\end{tabular}

Moreover, Fig. (10) showed that these composites suffered to gradual stiffness degradation with increasing fatigue cycles until they failed in a ductile fashion.

The microscopic test of the sample surface is presented in Fig. (11), it is obvious that the fracture zone was a semi ductile type and some plastic deformation could be observed.

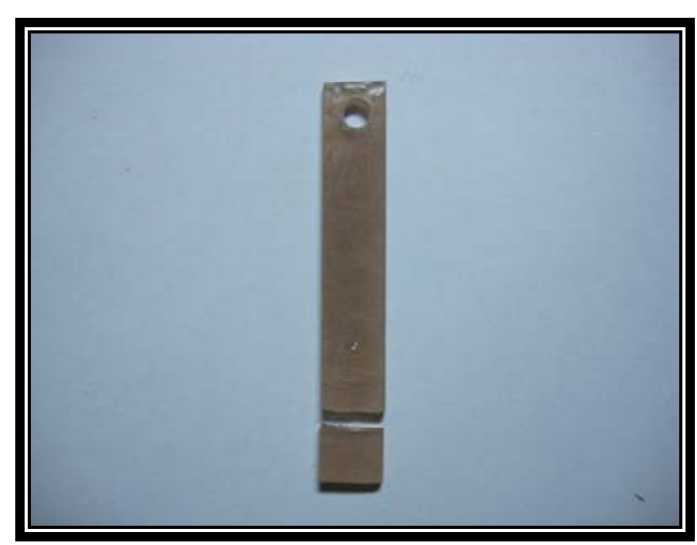

$6 \%$

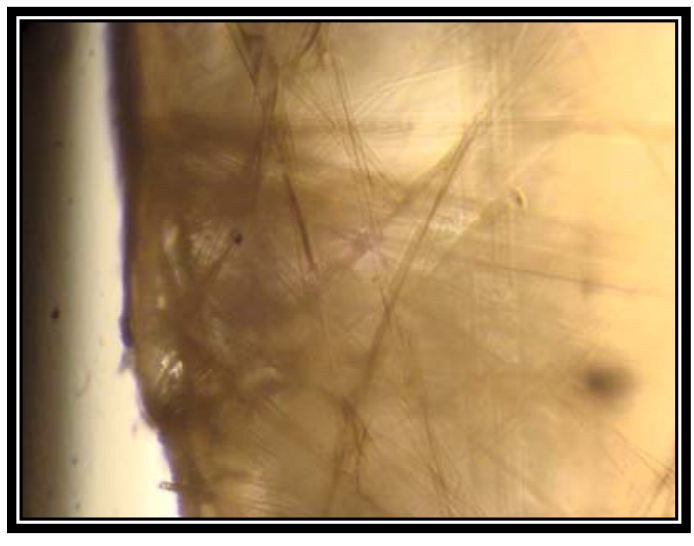

$6 \%, 200 X$

Fig. 11: Fractured surface of glass laminates fibers composite

Fig. (12) shows the accurance of striation through out the cross-section of the fractured zone. 


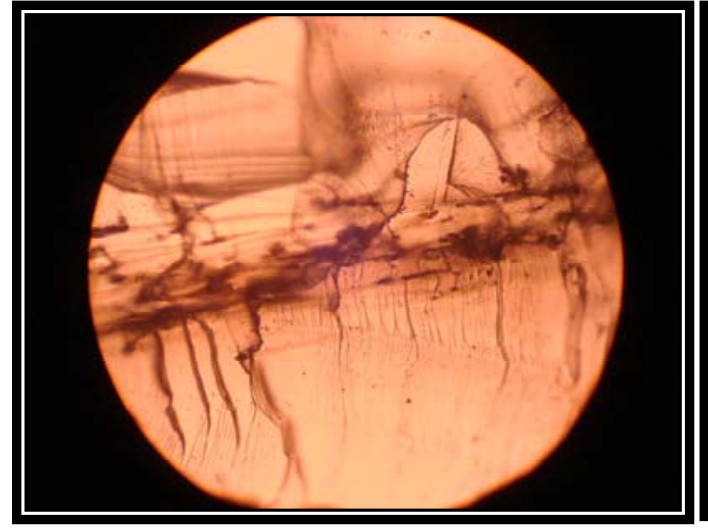

$1.25 \%, 100 X$

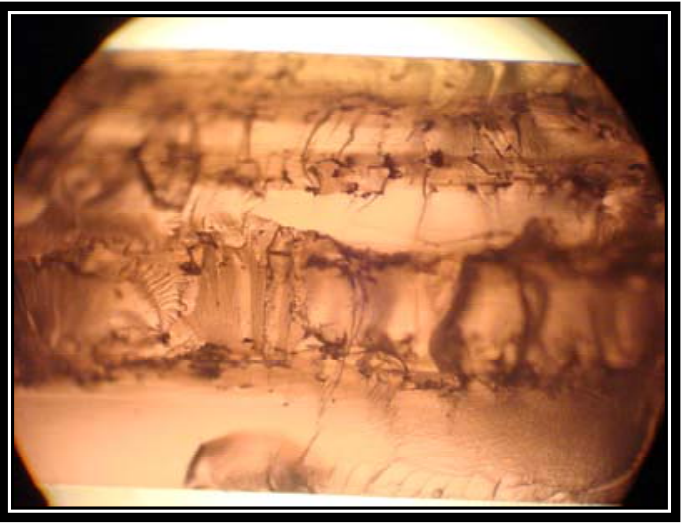

$4.9 \%, 100 X$

Fig.12: Fractured regions of glass laminates fibers composite

As indicated from Fig. (12), the damage is in the form of micro cracks which first appear on the outer surface and act as sharp notches. Some of these micro cracks extend and/or join to form critical cracks, which extend into the interior of the specimens and stopped by the presence of laminate glass fiber which acts as a shield against extended crack, then start to propagate from another region along the longitudinal laminates.

The cracks are, in most cases, oriented in a direction normal to the principal stress orthogonal to the fibers direction, exceed the strength of the matrix, but do not always cover the whole width of the specimen.

Propagation of the cracks near the interface of the layer will produce high interlaminar stresses which generate interlaminar cracks that cause the delamination within the laminate. This mechanism of propagation continued throughout the layer / layers of the specimen, however the increases of the number of layers, will causes to a time delay for the final fracture, and the intensity of the damage zone, indicated by the number of cracks increased with number of cycles.

\section{Fatigue behavior of glass continuous fiber composite}

Fatigue tests were performed with different values of imposed stress. Fig. (13) shows the stress curves versus the number of cycles, for composites specimens with different weight fraction of fibers. 


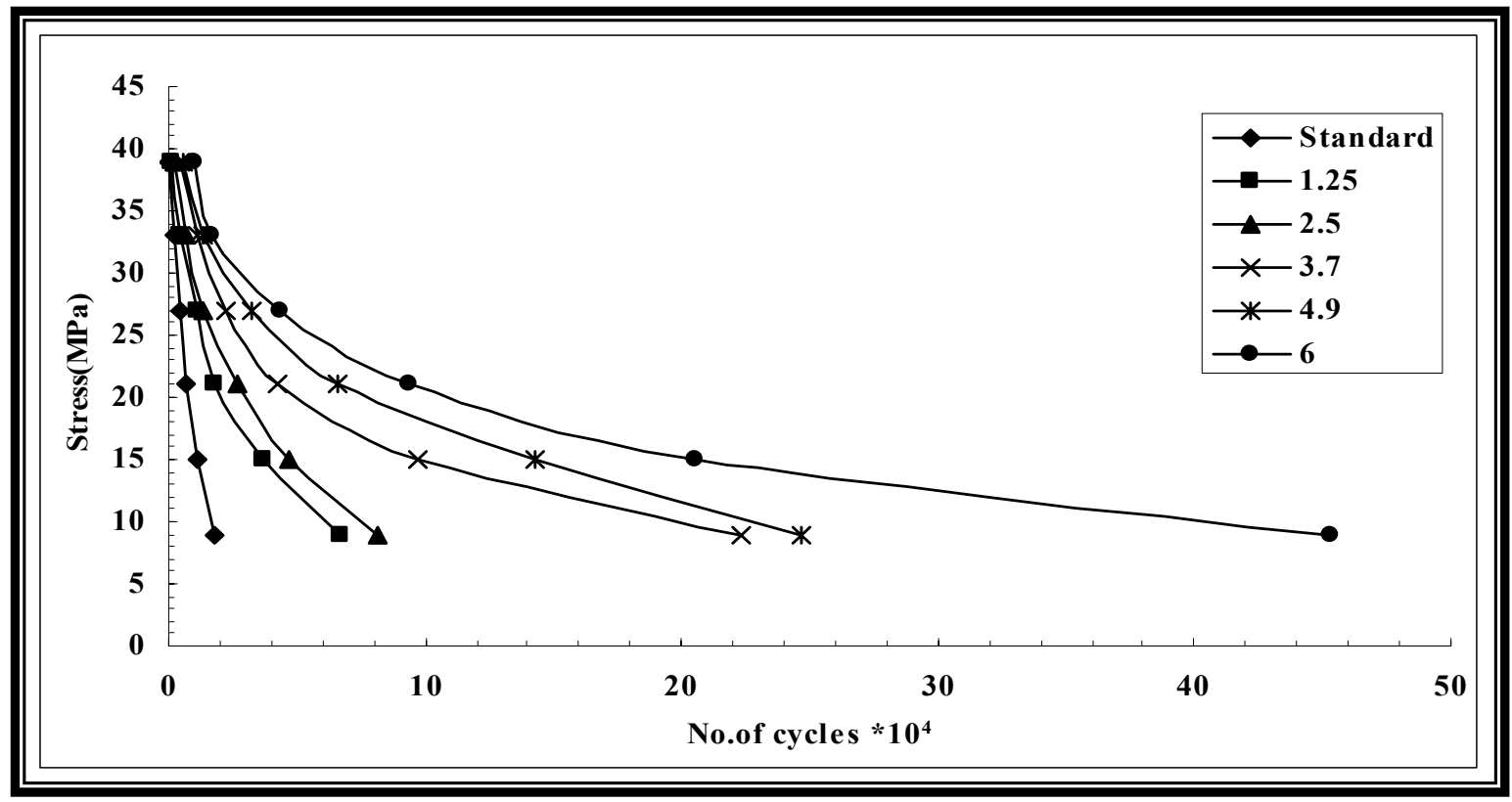

Fig. 13: Fatigue life of glass continuous fibers composite

It can seen that the number of cycles up to fracture for the composites was decreased with an increase in the applied stress (load).

Graphical comparison of experimental results between unreinforced and reinforced specimens gives an idea of different behavior, of the two materials during a fatigue load.

A comparison of the obtained results shows that there is an improvement in fatigue life of this composite as compared with the nonreinforcement specimen, for example improvement in fatigue life approaches (4) times more than the standard sample, this is because the fibers bear most of the applied load.

This improvement was observed in all sample, which could be reached up to (25) times as compared to standard when the concentration of reinforcement materials increased up to (6wt $\%)$, as shown in Table (4). This means that these composites showed a better resistance against fatigue failure.

Table 4: Fatigue life $V_{S}$ the weight fraction of continuous fibers composite

\begin{tabular}{|c|c|c|c|}
\hline $\begin{array}{c}\text { Weight fraction } \\
(\mathbf{w t} \%)\end{array}$ & $\begin{array}{c}\text { Fatigue strength } \\
(\mathbf{M P a})\end{array}$ & $\begin{array}{c}\text { Fatigue life (No. } \\
\text { of cycle) }\end{array}$ & $\begin{array}{c}\text { Times of } \\
\text { improvement }\end{array}$ \\
\hline 0 & 9 & 17844 & $0 \mathrm{X}$ \\
\hline 1.25 & 9 & 66422 & $4 \mathrm{X}$ \\
\hline 2.5 & 9 & 81341 & $4.5 \mathrm{X}$ \\
\hline 3.7 & 9 & 223153 & $12.5 \mathrm{X}$ \\
\hline 4.9 & 9 & 246232 & $14 \mathrm{X}$ \\
\hline 6 & 9 & 453492 & $25 \mathrm{X}$ \\
\hline
\end{tabular}


Fig. (14) shows the surface regions using optical microscope.

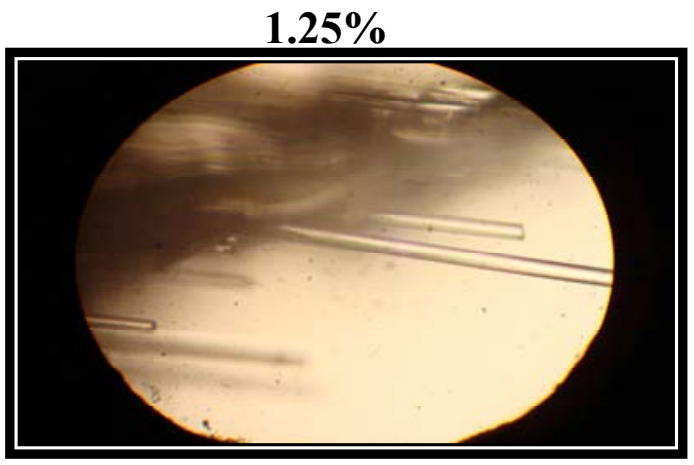

$1.25 \%, 40 X$

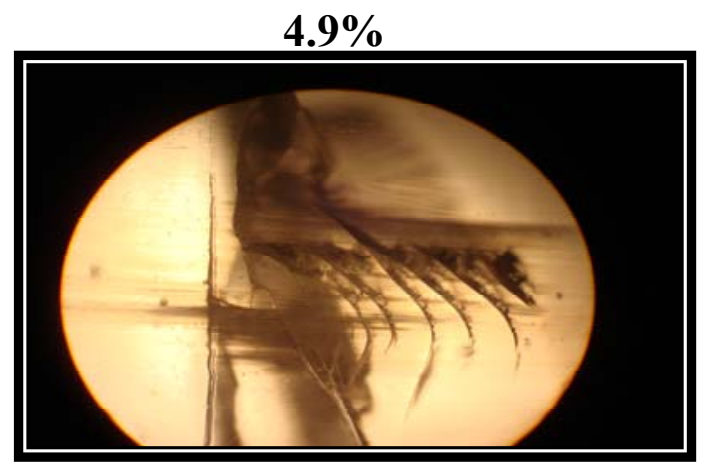

$2.5 \%, 40 X$

$4.9 \%, 40 X$

$6 \%, 40 X$

The fiber pullout is clearly observed which means that there's a poor interfacial bonding between fiber and matrix that produces a relatively clean surface over the pulled out fibers due to a greater extent of delamination. While the glass laminates fibers composite proved that there was a strong interfacial adhesion between the fibers and matrix as a mentioned before.

The cross-section photomicrograph of broken sample is shown in Fig. (15). 